\title{
EDITORIAL
}

\section{Mental health and life on a small island}

\author{
David Skuse
}

University of London Institute of Child Health, London, UK; email: d.skuse@ucl.ac.uk

\section{doi:10.1192/bji.2018.3}

(c) The Author 2018. This is an Open Access article, distributed under the terms of the Creative Commons Attribution-

NonCommercial-NoDerivatives licence (http://creativecommons. org/licenses/by-nc-nd/4.0/), whic permits non-commercial re-use, distribution, and reproduction in any medium, provided the original work is unaltered and is properly cited. The written permission of Cambridge University Press must be obtained for comPress must be obtanned for commercial reuse or in order to $\mathrm{cre}$ ate a derivative work.

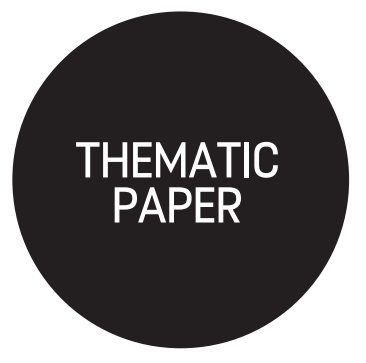

Desert Island Discs has been a popular radio programme in the UK since 1942. Guests are asked to choose the discs they would most want to save, in order to make life on a desert island bearable after shipwreck. The potential impact of loneliness on the unfortunate celebrity's mental health is rarely discussed. Yet the inhabitants of small islands do suffer mental health problems, and our theme this month is a discussion of the ways in which services to assist them are being delivered. Yutaro Setoya and Dévora Kestel discuss how the World Health Organization is offering support to several small island states in the Pacific and the Caribbean through the Mental Health Gap Action Programme. Training has been delivered to a few Caribbean islands over the internet as a pilot project, and the strategy has caught on with such enthusiasm that it is going to be rolled out to many more small island states soon.

Far from the sunny Caribbean are the Falkland Islands (or Malvinas). These islands are geographically remote and have a small population of mainly British descent. There are frequent visitors from ships sailing to the Cape or Antarctica, as well as many fishing vessels, with fishermen bringing their own problems to the attention of the medical services available there. Remarkably, because the Falkland Islands are
British Territories, the provision of legislation for the management of mental health problems is subject (at least for now) to the European Convention of Human Rights. Updating the former Mental Health Ordinance for the islands, which was not compliant, brought about new opportunities and demands for training local staff. Karen Rimicans and Dr Tim McInerny provide a fascinating insight into the challenges faced by such a remote community.

Finally, we consider the provision of psychiatric services to the Shetland Isles, which lie well north of Scotland and not too far from Norway. Martin Scholtz and Almarie Harmse give us a glimpse into the history of these islands, which are warmed by the Gulf Stream and whose population is rapidly recovering from its lowest point over the past 50 years. The economy of the islands has been improving owing to initiatives in the oil and the seafood industries, and with this growth has come a demand for more medical and mental health services. Dependency on mainland facilities for major mental health support poses a range of logistical problems, and so novel crisis and home treatment protocols have been introduced, which seem highly effective in reducing admissions. The small island experience has been a positive one for the authors of this contribution to our theme this month.

\section{WHO Mental Health Gap Action Programme implementation in the Small Island Development States: experience from the Pacific and English-speaking Caribbean countries}

\author{
Yutaro Setoya $^{1}$ and Dévora Kestel ${ }^{2}$
}

${ }^{1}$ Technical Officer Mental Health, Division of Pacific Technical Support, Western Pacific Region, WHO, Nuku'alofa, Tonga; email setoyay@who.int

${ }^{2}$ Unit Chief, Mental Health and Substance Use, Pan American Health Organization (PAHO/ WHO), Washington, DC, USA
Owing to the relatively small population sizes and remoteness of the Small Island Development States (SIDS), their mental health systems face many common difficulties. These include having few mental health specialists per country, limited access to mental health services and low awareness.
To overcome these limitations, the World Health Organization (WHO) Mental Health Gap Action Programme (mhGAP), which aims to decrease the treatment gap by training non-specialists, was implemented in more than 20 Pacific and English-speaking Caribbean countries. Many lessons were learnt 